the short arm of chromosome $6 .{ }^{6}$ Autosomal recessive inheritance has been proposed as its mode of transmission, ${ }^{67}$ but further confirmation is awaited. At present it seems likely that other factors, possibly other genes, modify the expression of a juvenile myoclonic epilepsy gene on chromosome 6 .

The recognition that non-pharmacological factors, such as emotional stress, sleep deprivation, alcohol use, and menses, seem to precipitate seizures ${ }^{13}$ allows patients to gain some control of their seizures; most patients, however, will require treatment with drugs. Unfortunately, no prospective, controlled studies of drug treatment for juvenile myoclonic epilepsy have been performed and current information on use of anticonvulsant drugs has been derived exclusively from retrospective studies and anecdotal reports. ${ }^{8}$ Currently the drug of choice is sodium valproate, ${ }^{9}$ which completely suppresses seizures in $80-90 \%$ of patients. ${ }^{7}$ Treatment of those patients who respond poorly to valproate is difficult and often requires more than one antiepileptic drug. No other single drug stands out as the ideal second line agent. Though anecdotal reports suggest that most other anticonvulsant drugs may be helpful, overall results are disappointing. In many patients carbamazepine exacerbates myoclonus and juvenile myoclonic epilepsy. ${ }^{10-13}$

Juvenile myoclonic epilepsy usually persists throughout life, and patients in their seventh decade have been reported. Attempted drug withdrawal, even after complete suppression of seizures for two or more years, leads to relapses in $80-90 \%$ of patients. ${ }^{128}$ It is therefore important that a correct diagnosis is made so that patients with juvenile myoclonic epilepsy may be advised that treatment is usually required life long.

P L TIMMINGS

Lecturer in Clinical Pharmacology A RICHENS

Professor of Pharmacology and Therapeutics

Department of Pharmacology and Therapeutics,

University of Wales College of Medicine,

Cardiff CF4 4XN

1 Janz D. Epilepsy with impulsive petit mal. Acta Neurol Scand 1985;72:449-59.

Penry JK, Dean JC, Riela AR. Juvenile myoclonic epilepsy: long-term response to therapy Epilepsia 1989;30(suppl 4): 19-23.

Dreifuss FE. Juvenile myoclonic epilepsy: characteristics of a primary generalised epilepsy. Epilepsia 1989;30(suppl 4):1-7.

4 Obeid T, Panayiotopoulos CP. Juvenile myoclonic epilepsy: a study in Saudi Arabia. Epilepsia 1988;29:280-2.

5 Delgado-Escueta AV, Bascal FE. Juvenile myoclonic epilepsy of Janz. Neurology 1984;34:285-94 6 Delgado-Escueta AV, Greenberg DA, Treiman L, Liu A, Sparkes RS, Barbetti A, et al. Mapping the gene for juvenile myoclonic epilepsy. Epilepsia 1989;30(suppl 4):8-18.

7 Panayiotopoulos CP, Obeid T. Juvenile myoclonic epilepsy: an autosomal recessive disease. Ann Neurol 1989;25:440-3.

8 Resor SR Jr, Resor LD. The neuropharmacology of juvenile myoclonic epilepsy. Clin Neuropharmacol 1990;13:465-91.

9 Sharmacol 1990;13:465-91.

9 Sodium valproate editorial]. Lancet 1988;ii:1229-31.
10 Clement MJ, Wallace SJ. Juvenile myoclonic epilepsy. Arch Dis Child 1988;63:1049-53.

11 McKee PJW, McGinn G, Larkin JG, Brodie MJ. Myoclonic epilepsy - pitfalls in diagnosis and management. Scott Med J 1991;36:18-9.

2 Snead OC, Hosey LC. Exacerbation of seizures in children by carbamazepine. $N$ Engl $\mathcal{Y}$ Med 1985;313:916-21.

13 Shields WD, Saslow E. Myoclonic, atonic and absence seizures following institution of carbamazepine therapy in children. Neurology 1983;33:1487-9.

\title{
Ecstasy and the dance of death
}

\section{Severe reactions are unpredictable}

Ecstasy is the popular name for 3,4-methylenedioxymethamphetamine, a synthetic amphetamine derivative. Patented in 1914 by the E Merck Company as an appetite suppressant, it lay virtually forgotten until the 1970s. Apart from a mild amphetamine-like stimulant effect it induces a feeling of euphoria and benevolence and, although it tends to enhance perception, its hallucinogenic potential is low. Because of these properties its psychotherapeutic potential began to be explored in fields as divergent as marriage guidance, alcoholism, and enhancement of perception in elderly people-all without benefit.

While its therapeutic possibilities were being discarded its potential for misuse was being discovered, and its use in the United States as a recreational drug became widespread. As a result it was banned there in 1985. In Britain it is banned under the Misuse of Drugs Act 1971 as a class A drug. It is also a schedule 1 drug, indicating that it has no medicinal uses and requires a Home Office licence to give it.

Retrospective questioning of 100 users of 3,4-methylenedioxymethamphetamine showed that 90 experienced a feeling of closeness to others. ${ }^{1}$ It has, however, many adverse effects. In one study $75-150 \mathrm{mg}$ of pure 3,4-methylenedioxymethamphetamine was given orally to 29 volunteers by psychotherapists. ${ }^{2}$ All 29 experienced undesirable physical symptoms: 28 lost their appetite, 22 had trismus or bruxism (grinding of the teeth), nine had nausea, eight had muscle aches or stiffness, and three had ataxia. Sweating was common, and tachycardia and hypertension were recorded: Afterwards, 23 noted fatigue for hours or days, and 11 had insomnia.

In Britain the drug is taken orally as tablets or capsules with a 3,4-methylenedioxymethamphetamine content of about 50 - $150 \mathrm{mg}$; the street price is around $£ 15$ for a single dose. Tolerance occurs; some users increase the dose over weeks or months of use to as many as $\mathbf{1 0}$ or more tablets during the course of an evening. The most important difference between the American and British experience of the drug is that while it tends to be taken alone or at parties in the United States, it is used in Britain almost exclusively as a "dance drug."

At the currently popular "rave" parties the dancing is hard and fast so that the pharmacological effects of the drug may be compounded by physical exertion. Animal studies show that the drug may cause excessive heat production due to serotoninergic mechanisms, which is greater at high ambient temperatures. ${ }^{3}$ Very few cases of severe or fatal reactions have been recorded in the United States despite extremely widespread use. ${ }^{4}$ In Britain at least seven deaths and several severe adverse reactions have followed its use as a dance drug. ${ }^{5}$ Previous experience of the .Jrug is no guarantee of safety.

The case report 'n page 29 is typical of the acute severe complications which may occur. ${ }^{6}$ Convulsions, collapse, hyperpyrexia, disseminated intravascular coagulation, rhabdomyolysis, and acute renal failure may all follow ingestion of 3,4-methylenedioxymethamphetamine as a dance drug; complications may escalate in number and severity if the patient does not receive treatment soon enough. Fortunately, the patient described in the case report recovered following intensive supportive treatment.

Drug agencies are aware of the risk of hyperthermia and advise those who use the drug to wear loose clothing, to drink liquid to facilitate thermoregulation, and to stop dancing when feeling exhausted. Some club owners have provided 
"chillout" rooms with seating and air conditioning to help cooling. For the patient who is taken acutely ill medical management is urgent and includes control of convulsions, measurement of core temperature, rapid rehydration, and possibly the use of dantrolene and active cooling measures.

Some people taking the drug for the first time find the effects disturbing and may complain to their general practitioner of paranoia, hallucinations, insomnia, tachycardia, or muscle stiffness, including trismus or bruxism. In general, all that is needed is reassurance as these acute effects usually resolve within 48 hours. Regular users frequently chew gum to overcome the effects on their jaw muscles; they may present with weight loss, exhaustion, jaundice, "flashbacks," irritability, paranoia, depression, or psychosis. ${ }^{8-14}$

The long term effects of 3,4-methylenedioxymethamphetamine will take time to be documented in detail. At present it seems that repeated use may cause hepatic damage; it is worth mentioning ecstasy when asking about drug habits in young people presenting with unexplained jaundice. ${ }^{5}$ Perhaps the most disturbing aspect of the drug's misuse is the possibility of long term psychiatric effects. Although the drug acts as a neurotoxin at serotoninergic terminals, ${ }^{15}{ }^{16}$ there is no evidence yet that it causes permanent brain damage in man. There have, however, been a few case reports of psychiatric illness ${ }^{10-14}$ but the numbers affected are undoubtedly greater than this'; it could take years until the full toll of psychiatric disorders induced by 3,4-methylenedioxymethamphetamine, including depression and suicide, is established. Claims by misusers and agencies that ecstasy is "safer than alcohol" seem premature. Although the drug does not seem addictive, relaxing the strict legal controls over a drug whose "benefits" are debatable and whose risks are evident would be unwise.

JOHN A HENRY

Consultant Physician,

National Poisons Information Service, $\mid$ Guy's Hospital,

London SE1 9RT

1 Peroutka SJ, Newman $\mathrm{H}$, Harris $\mathrm{H}$. Subjective effects of 3,4-methylenedioxymethamphetamine recreational users. Neuropsychopharmacology 1988:1:273-7.

Greer $G$, Tolbert $R$. Subjective reports of the effects of 3,4-methylenedioxymethamphetamine in clinical setting. 7 Psychoactive Drugs 1986;18:319-27.

3 Gordon CJ, Watkinson WP, O'Callaghan JP, Miller DB. Effects of 3,4 methylenedioxymethamphetamine on autonomic thermoregulatory response of the rat. Pha macol Biochem Behav 1991;38:339-44.

4 Dowling GP. Human deaths and toxic reactions attributed to 3,4-methylenedioxymethamphetamine and MDEA. In: Peroutka SJ, ed. Ecstasy: the clinical, pharmacological, and neurotoxicological effects of the drug 3,4-methylenedioxymethamphetamine. Norwell, Massachusetts: Kluwer, 1990:63-75.

Henry JA, Jeffreys KJ, Dawling S. Toxicity and deaths due to 3,4-methylenedioxymethamphetamine ("ecstasy"). Lancet (in press).

6 Fahal IH, Sallomi DS, Yaqoob M, Williams PS, Bell GM. Ecstasy induced acute renal failure. BMF 1992;305:29.

7 Screaton GR, Singer M, Cairns HS, Thrasher A, Sarner M, Cohen SL. Hyperpyrexia and rhabdomyolysis after 3,4-methylenedioxymethamphetamine ("ecstasy") abuse. Lancet 1991;339:677-8.

Creighton FJ, Black DL, Hyde CE. "Ecstasy" psychosis and flashbacks. $\mathrm{Br} \mathcal{F}$ Psychiatr 1991;159:713-5.

9 Winstock.AR. Chronic paranoid psychosis after misuse of 3,4-methylenedioxymethamphetamine. BMF 1991;302:1150-1.

10 McGuire $P$, Fahy T Chronic paranoid psychosis after misuse of 3,4-methylen dioxymethamphetamine ("ecstasy"). BM7 1991;302:697.

1 Schifano $\mathrm{F}$. Chronic atypical psychosis associated with 3,4-methylenedioxymethamphetamin ("ecstasy") abuse. Lancet 1991;338:1335.

12 Whitaker-Azmitia PM, Aronson TA. "Ecstasy" (3,4-methylenedioxymethamphetamine)-induce panic. Am $\mathcal{F}$ Psychiatry 1989;146:119.

13 Climco RP, Rohrich. H, Sweeney DR, Al-Razi J. Ecstasy-a review of '3, methylenedioxymethamphetamine and MDA. Int $\mathcal{F}$ Psychiatry Med 1987;16:359-71

14 Benazzi F, Mazzoli M. Psychiatric illness associated with "ecstasy." Lancet 1991;338:1520.

15 Ricaurte G, Bryan G, Strauss L, Seiden L, Schuster C. Hallucinogenic amphetamine selectively destroys brain serotonin nerve terminals. Science 1985;229:986-8.

16 McKenna DJ, Peroutka SJ. The neurochemistry and neurotoxicity of 3,4-methylenedioxymethamphetamine "ecstasy, "f Neurochem 1990; 54:14-22.

\section{Health and safety on the farm}

\section{Time to raise their status}

Those who idealise rural life in Britain may be surprised to learn that many of our farmworkers face a wider range of hazards than most other workers and that preventive measures lag behind those in most other occupations. Agriculture shares with construction, mining, and fishing the dubious distinction of being a target industry for action in this the European year of safety, hygiene, and health protection at work, ${ }^{1}$ all being among the occupations at highest risk for accidental death and injury.

The agricultural sector averages one fatal injury to a worker every week and one to a member of the public every month. Farmers' health may also be affected by exposure to highly toxic chemicals, organic dusts, zoonotic infections, and a wide range of adverse environmental conditions. ${ }^{2}$ Furthermore, the hazards may extend to farmworkers' families and to visitors, whether or not they are engaged in routine farm work. Concerns also exist about the possible effects of farming practices-for example, the use of pesticides-on the environment and public health. ${ }^{3}$

Our knowledge of the extent of these problems among this scattered and diminishing working population remains sparse. As in the United States, ${ }^{4}$ there is a recognised need for improved surveillance of disease and injury; for more epidemiological investigation of morbidity, including toxicological effects, and mortality; for further study of the associated risk factors; and for devising effective interventions.

If confirmation of these needs was required it has been provided by three papers published in this journal ${ }^{5}$ (p 25) (p 23). ${ }^{7}$ Cameron and Bishop compared the number of adults presenting with farm related injuries to a hospital in rural west Wales with official notifications of serious accidents to the Health and Safety Executive: they found that only a quarter of the major injuries were reported and that official statistics may grossly underestimate overall injury rates. ${ }^{6}$. Unless such accidents are notified intervention by the Agricultural Inspectorate to prevent further mishap is unlikely; most agricultural accidents are related to falls or falling objects, machinery, or livestock - a key factor being the failure to maintain equipment and buildings.

A wider study by the same authors shows how children under 16 account for a disproportionate number of disabling injuries and workplace deaths. ${ }^{7}$ And Croft $e t$ al, by adding further to evidence emerging from other countries suggesting that osteoarthritis should be recognised as an occupational disease in farmers, highlight the importance of lifting and other physical stresses on farms in the causation of degenerative musculoskeletal disease. ${ }^{5}$

Other occupationally related disorders, such as farmer's lung and asthma and zoonotic infections with organisms such as Leptospira hardjo, which is common in dairy workers, ${ }^{8}$ are also unlikely to be recognised because their symptoms are often non-specific. These conditions should be notified by the farm employer or the self employed farmer under the Reporting of Injuries, Diseases and Dangerous Occurrences Regulations (RIDDOR). Even if they come to the farmer's 